\title{
Lenticular burns following argon panretinal photocoagulation
}

\author{
Steven M Bloom, Charles F Mahl, Sheldon B Schiller
}

\begin{abstract}
Photocoagulation burns of the crystalline lens are a rare complication of posterior segment laser surgery. These burns occur more commonly in eyes with cataracts and with small, high-power, long-duration argon blue-green burns. We describe the first occurrence of lenticular burns caused by a fractured laser fibre optic cord.

(Brf Ophthalmol 1992; 76: 630-631)
\end{abstract}

Photocoagulation burns of the crystalline lens are a rare complication of posterior segment laser surgery..$^{1-5}$ Focal white, cylindrical anterior cortical burns, which are usually non-progressive, appear immediately during the photocoagulation treatment. This complication is thought to be more common with long duration, high intensity, argon blue-green photocoagulation burns, though it has also been reported following krypton-red photocoagulation. ${ }^{6}$ Focal anterior lens opacities have also been reported recently adjacent to inadvertent iris burns following indirect laser photocoagulation.?

We report a patient who suffered multiple lenticular burns owing to highly variable power output from a fractured laser fibreoptic cord.

\section{Case report}

A 60-year-old woman with diabetes mellitus of 20 years' duration was evaluated in October 1988 for diabetic retinopathy. Vision was 20/30 in each eye due to minimal bilateral nuclear sclerotic changes. Clinically significant macular oedema and mild background diabetic changes were seen in both eyes.

The macular oedema resolved following argongreen focal laser treatment and she did well until August 1990 when she developed peripupillary iris neovascularisation and proliferative diabetic retinopathy in both eyes. Vision was decreased to $20 / 40$ in the right eye and 20/50 in the left eye due to mild progression of the bilateral nuclear sclerosis. One day prior to laser surgery the argon-krypton laser was serviced and upgraded to produce parfocal burns. Argon green panretinal photocoagulation was attempted in the right eye through a panfunduscopic contact lens using a $500 \mu \mathrm{m}$ spot size and $0 \cdot 2$ second duration. Adequately intense retinal burns could not be obtained despite a maximal power of $1 \cdot 10 \mathrm{~W}$. Argon blue-green laser was then attempted with powers up to $2 \cdot 23 \mathrm{~W}$ before retinal burns were obtained.

Visualisation of the fundus deteriorated during the course of the laser treatment and the procedure was discontinued after 241 burns had been applied. Multiple focal, cylindrical, yellow-white cortical lenticular opacities were seen when the contact lens was removed (Fig 1). These burns obstructed the visual axis and prevented any additional laser treatment. The fibreoptic cord connecting the laser with the slitlamp delivery system was later found to be bent and internally fractured. Minimal fibreoptic movement resulted in widely variable burn intensities. The machine was again serviced 1 day after the photocoagulation treatment. The laser produced parfocal and accurately sized burns. However, the power output varied between $25-100 \%$ of the selected power depending on movement of the fibreoptic cord. The fractured cord was removed from the laser suite by the servicing technician for later analysis.

Vision in this eye 2 weeks later was 20/200 with essentially no change in the cortical opacities. Phacoemulsification with placement of a posterior chamber intraocular lens was performed on 17 September 1990. Panretinal photocoagulation was then completed in both eyes over the next 2 months. All iris and posterior segment neovascularisation subsequently involuted. Vision 1 year following cataract surgery in the right eye was $20 / 40$.

The manufacturer has informed us that they were unable to carry out an in depth visual inspection of the cord because the removal of plastic coating from the underlying fibreoptic was not possible.

\section{Discussion}

The fractured fibreoptic cord produced highly variable power outputs during our patient's laser

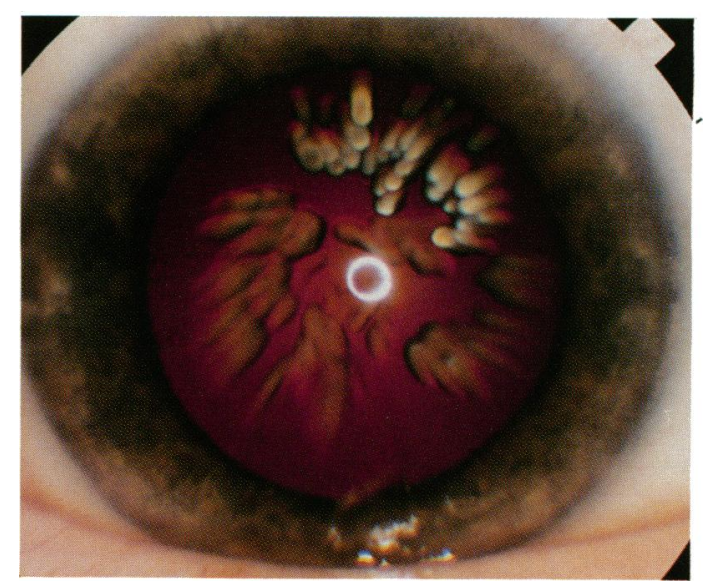

Figure 1 Multiple cortical lenticular burns immediately following argon panretinal photocoagulation. 
treatment. Powers of up to $2 \cdot 23 \mathrm{~W}$ were selected, but this delivered powers to the cornea varying from 0.56 to $2.23 \mathrm{~W}$. We postulate that initially the laser machine was delivering a much lower power than was selected. At some point during the treatment, possibly after switching to argon blue-green, the fibreoptic cord may have shifted and produced a firmer contact between the fractured ends. This caused a much more intense burn to be delivered to the eye and resulted in the focal lenticular burns described above. Our patient's pre-existing nuclear sclerotic cataract may have predisposed her to developing this complication.

Several precautions should be taken to prevent laser-induced lenticular burns. Small, longduration, high-power, argon blue-green burns should be avoided if possible. This is especially true in the presence of a nuclear-sclerotic cataract. In addition, the laser surgeon should be aware that inability to obtain adequately intense or variably intense retinal burns may be caused by a fractured fibreoptic laser cord. Adequate precautions should be taken in the laser suite to protect this cord from injury. In addition, careful preoperative checking of the laser should be made after every service call.

1 Zweng HC, Little HL, Hammond AH. Complications of argon laser photocoagulation. Trans Am Acad Ophthalmol Otolaryngol 1974; 78: 195-204.

2 Lakhanpal V, Schocket SS, Richards RD, Niraukari VS. Photocoagulation-induced lens opacity. Arch Ophthalmol 1982; 100: 1068-70.

3 McCanna PM, Chandra SR, Stevens TS, Myers FL, de Venecia G, Bresnick GH. Argon laser-induced cataract as a complication of retinal photocoagulation. Arch Ophthalmol 1982; 100: 1071-3.

4 Shapiro A, Tso MOM, Goldberg MF. Argon laser-induced cataract: a clinicopathologic study. Arch Ophthalmol 1984; 102: $579-83$.

5 Gamel JW, Eiferman RA. Cataracts produced by argon laser photocoagulation. Arch Ophthalmol 1983; 101: 665.

6 Cartwright MJ, Blair CJ, Stratford TP. Krypton laser-induced lens opacity as a complication of panretinal photocoagulation. Ann Ophthalmol 1990; 22: 463-6.

7 Irvine WD, Smiddy WE, Nicholson DH. Corneal and iris burns with the laser indirect ophthalmoscope. Am $\mathcal{F}$ Ophthalmol 1990; 110: 311-3. 